\title{
Comment on: Eruptive Syringoma - Two Cases with Dermoscopic Features
}

\author{
Hudson Dutra Rezende ${ }^{a}$ Ana Carolina Trombetta Madia ${ }^{b}$ \\ Bruna Margatho Elias ${ }^{a}$ Thaís de Freitas Peraro ${ }^{a}$ Sandra Lopes Mattos Dinato ${ }^{a}$ \\ aDepartment of Dermatology, Lusiada University Fundation, Sao Paulo, Brazil; bermatologist, Private Practice, \\ Sao Paulo, Brazil
}

\section{Dear Editor,}

We read with interest the article titled "Eruptive Syringoma: Two Cases with Dermoscopic Features" recently published by Botsali et al. [1] in your journal. In daily practice, eruptive syringoma (ES) pictures a rare condition manifested by multiple skin-colored or slightly erythematous monomorphic papules that arise de novo mainly over the anterior trunk, neck, and axilla $[2,3]$. Affected patients may be misdiagnosed as having disseminated granuloma annulare, multiple trichoepitheliomas, eruptive vellus hair cysts, xanthoma disseminatum, and steatocystoma multiplex $[2,3]$. For such cases, dermoscopy may help anticipate the diagnosis.

Accordingly, Botsali et al. [1] defined three dermoscopic patterns of 2 patients with ES: (1) reticular brown lines on a faint erythematous background; (2) reticular vascular network; and (3) glittering white dots. As well mentioned by the authors, the presence of reticular brown lines or fine pigment network has been attributed to overlying basal hyperpigmentation and is observed in most patients with ES [4]. Meanwhile, the glittering whitish dots would represent a combination of cystic adnexal proliferations embedded in fibrous stroma, which in fact corresponds to other terms also described in the litera-

karger@karger.com www.karger.com/sad

(C) 2021 S. Karger AG, Basel

Karger" ture, such as tiny whitish dots, multifocal hypopigmented areas, and glittering yellow-whitish round structures [4, 5]. As of yet, this pattern has been exclusively reported on the vulvar region [1].

We recently evaluated a 32-year-old woman who complained of asymptomatic new onset papules distributed all over her chest and neck (Fig. 1a). Before a skin biopsy was taken and the diagnosis confirmed, we considered ES the main clinical hypothesis based on dermoscopic grounds. In accordance with Botsali et al.'s [1] observations, the 2 commonest dermoscopic patterns (reticular brown lines and reticular vascular network) were present in our case, but we also registered their coexistence with tiny whitish dots (Fig. 1b), featuring an interesting combination of 3 dermoscopic patterns on the same lesions.

Despite having similar clinical presentations, granuloma annulare, trichoepitheliomas, eruptive vellus hair cysts, xanthoma disseminatum, and steatocystoma multiplex are not expected to show reticular brown lines, reticular vascular network, and tiny whitish dots at once. We propose that for patients whose dermoscopy exhibits the three aforementioned patterns simultaneously, ES should be taken as the first diagnosis to be considered. 

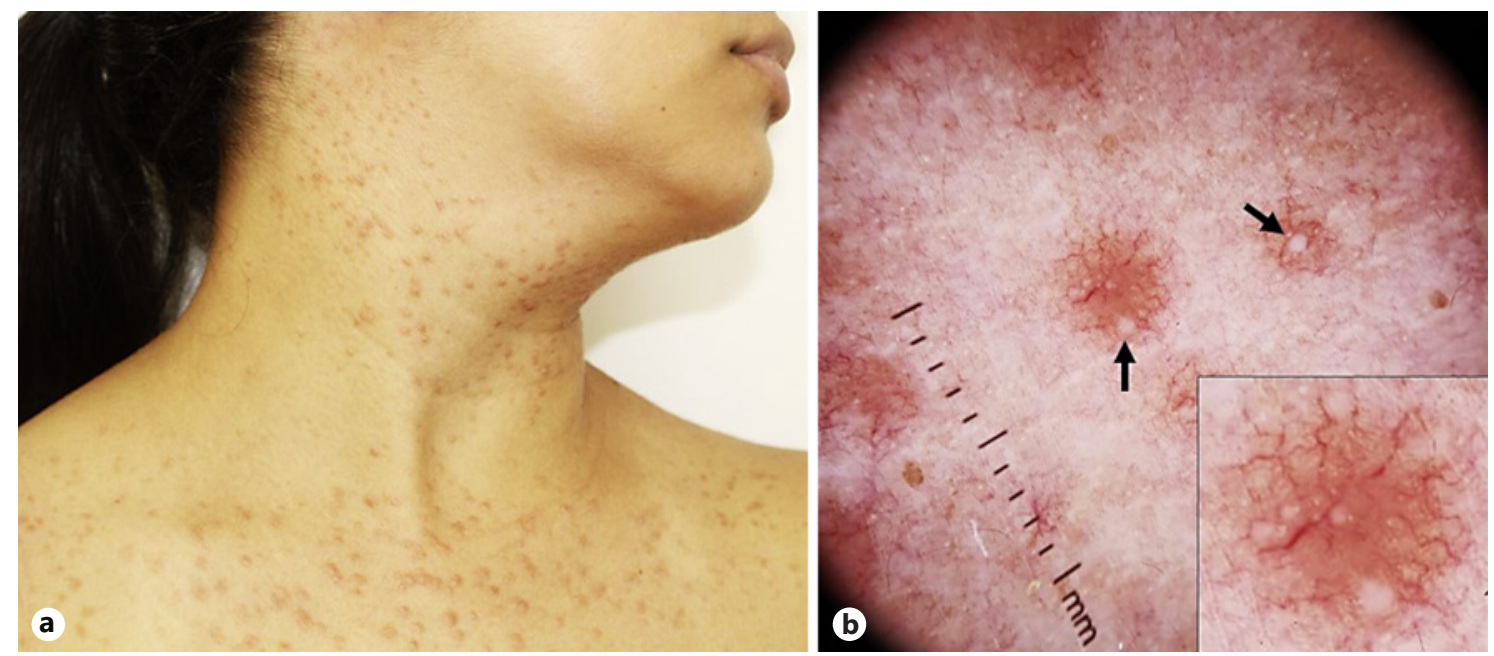

Fig. 1. Eruptive syringoma. a Clinical presentation: erythematous, monomorphic papules on the upper trunk and neck. b Dermoscopic features showing tiny whitish dots (arrows) coexisting with fine reticular brown lines on the background superimposed by demarcated reticular vascular network (inset).

\section{Statement of Ethics}

Written informed consent was obtained from the patient for publication of any accompanying images.

\section{Conflict of Interest Statement}

The authors have no conflicts of interest to declare.

\section{Funding Sources}

The authors have no funding to declare.

\section{Author Contributions}

Data collection and review of the literature, final concept of the manuscript, and writing adjustments and critique of the manuscript have been equally performed by all authors.

\section{References}

1 Botsali A, Caliskan E, Coskun A, Tunca M. Eruptive syringoma: two cases with dermoscopic features. Skin Appendage Disord. 2020;6(5):319-22.

2 Huang A, Taylor G, Liebman TN. Generalized eruptive syringomas. Dermatol Online J. 2017;23(9):17.

3 Hida T, Okura M, Kamiya T, Yamashita T. Nagashima-type palmoplantar keratosis caused by compound heterozygous muta- tions in SERPINB7. Eur J Dermatol. 2015; 25(2):202-3.

4 Taneja G, Hazarika N, Bhatia R. Eruptive syringomas on the neck: clinicopathological and dermoscopic features. Dermatol Pract Concept. 2021;11(2):e2021022.

5 Corazza M, Borghi A, Minghetti S, Ferron P, Virgili A. Dermoscopy of isolated syringoma of the vulva. J Am Acad Dermatol. 2017;76(2): S37-9. 